\title{
Una introducció a la química des de la cuina
}

\author{
Núria Solsona Pairó \\ IES Josep Pla, Barcelona
}

L'article descriu l'experiència portada a terme durant cinc anys a l'IES Josep Pla, a quart d'ESO, per fer la introducció i estudi dels conceptes bàsics de química en un context culinari, diferent del laboratori escolar tradicional. Es descriuen els inicis i l'evolució de l'experiència, els materials i la infraestructura necessària per portar-la a terme, així com les possibilitats de continuïtat de l'experiència.

\section{LA QUÍMICA DE LA CUINA, UN CRĖDIT VARIABLE}

Fa cinc anys, a l'I.E.S. Josep Pla de Barcelona, sense saber exactament què en sortiria, vaig començar a introduir en un crèdit variable de química de quart d'ESO, algunes activitats, textos i experiments relacionats amb l'àmbit culinari. Els dos primers cursos escolars, el crèdit "La Química de la cuina" anava adreçat majoritàriament a noies i nois que no volien seguir estudis de Batxillerat i que ja havien cursat el crèdit comú de química, sense massa èxit acadèmic. L'experiència va sorgir de la necessitat de buscar un context d'aprenentatge més proper i assequible a l'alumnat que permetés una mirada diferent sobre la química.

A l'ESO, en l'aprenentatge dels conceptes bàsics de química, l'alumnat disposa d'una sèrie d'experiències $i$ coneixements previs sobre substàncies i canvis que ha realitzat, per exemple, preparant un berenar o fent xocolata desfeta. Atès que habitualment el context d'aprenentatge en el qual es desenvolupa l'ensenyament de la química és el del laboratori escolar no és fàcil connectar amb les estructures prèvies de l'alumnat. En canvi, la cuina $i$ el context culinari faciliten que les noies i els nois puguin activar i utilitzar les seves experiències i les seves preferències amb els pastissos, la xocolata $i$ tot allò que sigui dolç.

Rosa Sensat en el seu llibre "Les Ciències en la vida de la llar", editat per l'Associació Protectora de l'Ensenyança Catalana el 1923, ja suggeria treballar amb fets de la vida quotidiana per a introduir els continguts científics.

Repensar l'ensenyament dels sabers científics ha estat sempre una de les característiques de la meva trajectòria professional $i$ això m'ha portat $a$ revalorar la relació entre els sabers de les dones i l'ensenyament de la química. I a buscar noves pràctiques educatives que contribueixin a crear pensaments i significats culturals que parteixin de l'experiència acumulada per les dones i facin circular l'autoritat femenina. Per tant, a més de l'objectiu didàctic de la meva proposta, volia revalorar la importància dels sabers de les dones en la ciència escolar i destacar el seu caràcter de tasca indispensable per a la vida de les persones i el bon funcionament de les famílies i la societat.

La idea de fons que m'ha portat a introduir el context culinari en la iniciació a la química està relacionada amb la concepció tradicional del currículum. Les autoritats educatives mitjançant el currículum seleccionen els continguts que cal ensenyar i aprendre per part de l'alumnat. Però els criteris de selecció dels continguts escolars segueixen la perspectiva androcèntrica majoritària en la nostra societat; és a dir, se centren en l'experiència i els sabers elaborats per homes.

Per abordar l'ensenyament des d'una perspectiva no sexista, crec que cal incorporar a la vida escolar els sabers i les experiències de les dones. Entre aquests sabers hi ha el que s'entén socialment com a esfera privada de la vida: el món reproductiu, la cura d'altri i l'àmbit domèstic.

\section{LA INICIACIÓ A LA QUÍMICA EN CONTEXT CULINARI}

A partir del tercer curs escolar, el crèdit variable "La química de la cuina" va desaparèixer i em vaig plantejar el repte d'introduir el context culinari en l'assignatura de química comuna de quart d'ESO, adreçada a tot l'alumnat. Per a això vaig elaborar 
una seqüència didàctica per treballar a l'aula el model de canvi químic utilitzant fenòmens culinaris (Solsona, 2003).

La seqüència didàctica inclou l'aprenentatge dels conceptes bàsics de química, és a dir el model de canvi químic. Les activitats d'aprenentatge científic són de diferents tipus: l'observació de les propietats de les substàncies, l'elaboració i comprensió de textos científics i la realització d'experiments que ajudin a la conceptualització. Estudiem les substàncies, els instruments i els processos que es realitzen a la cuina. També portem a terme diferents experiments on realitzem alguns dels canvis físics i químics que es fan a la cuina. Per exemple, preparem caramel de diferents maneres, fem pa torrat, galetes, pastissos, melmelades, escumes, mató a partir de la llet, etc.

Els dos primers anys d'experimentació de la química de la cuina, havíem d'utilitzar el forn de la cuina del menjador escolar i teníem dificultats per controlar la temperatura i el temps de cocció dels pastissos. Però els dos darrers anys ha millorat l'utillatge de la cuina-laboratori gràcies a les ajudes rebudes per part de l'Institut d'Educació de l'Ajuntament de Barcelona i, a la participació en el Projecte europeu Tempora.

En un laboratori de química, que reuneix les condicions higièniques necessàries per treballar amb aliments, tenim un forn, un microones, una cuina de plaques elèctriques, una batedora professional i l'utillatge necessari per fer les preparacions culinàries. Val a dir que els ajuts econòmics rebuts han servit per millorar la valoració de l'experiència, tant per part del Claustre com per les mares i els pares de l'alumnat.

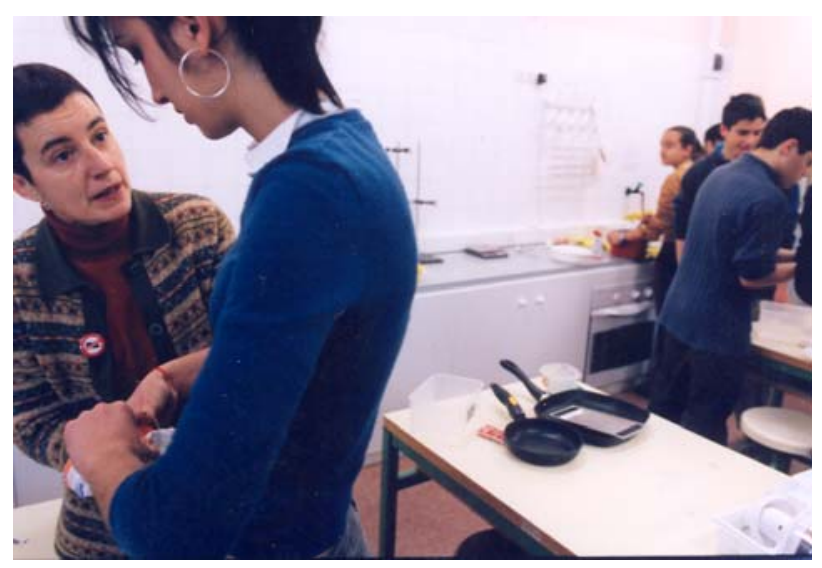

Fig. 1. Una vista del laboratori-cuina

Vull remarcar que fins i tot les habilitats culinàries de les noies i els nois han augmentat els darrers anys. I que la mateixa curiositat que tenen per llegir les instruccions de determinats jocs informàtics l'apliquen en el maneig d'estris com la batedora de varetes, per batre les clares a punt de neu, en bus- car una manera per fondre la xocolata per posar sobre d'un pastís, per cremar el sucre o en una mànega per posar la nata de les "profiteroles".

\section{EL PROCÉS DE MODELITZACIÓ DEL CANVI QUÍMIC}

A quart d'ESO, per iniciar el procés de modelització del canvi químic, partim de l'estudi de les substàncies més habituals a la cuina, com la sal, el sucre, l'oli i el vinagre. Proposo que l'alumnat expliqui les propietats de les substàncies, en base a la teoria cineticomolecular. Per treballar les dissolucions, les mescles i els col-loides, l'alumnat prepara, a la cuina-laboratori, esmorzars i berenars que són mescles i dissolucions. En concret, per a l'estudi dels collloides proposa la preparació de flams, gelatines, crema catalana i tot tipus de salses que constitueixen un conjunt de fenòmens culinaris adients.

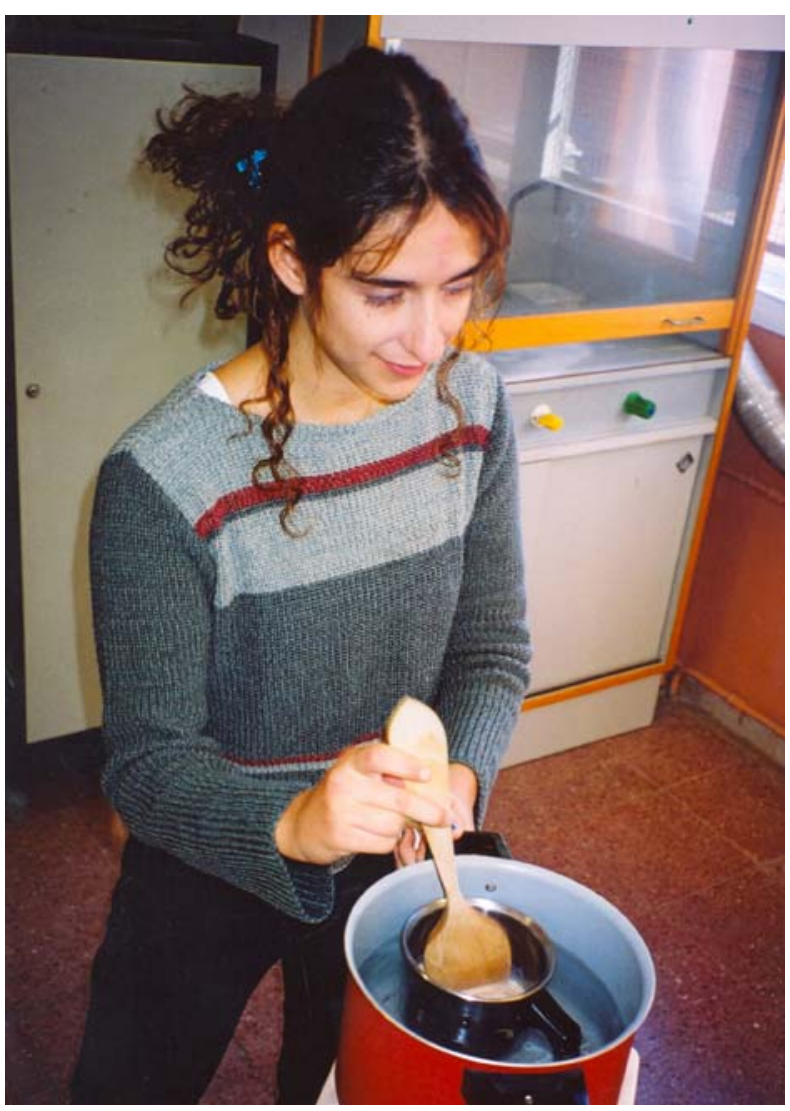

Fig 2. Preparació d'un col·loide: xocolata desfeta

L'estudi de les dissolucions, les mescles i els col-loides culinaris permet estudiar les diferents mides i formes d'agrupació de les partícules.

En el moment d'estudiar els factors que intervenen en el procés de dissolució d'una substància, comprenen millor la influència del grau de divisió 
del solut quan comparen la diferència que hi ha entre intentar dissoldre un terrós de sucre a la llet o bé posar la mateixa quantitat de sucre granulat a la llet. La influència de la velocitat de dissolució del solut en el dissolvent per a dispersar les partícules del solut ho veuen molt clar en l'acció que realitzen cada matí, en preparar-se la llet amb cola-cao per esmorzar. Finalment tota la classe coneix la diferència que hi ha entre dissoldre el cacau en la llet, segons que la llet sigui freda o calenta. Això els permet aprendre la influència de l'absorció de calor en el procés de preparar la dissolució.

L'elaboració de pa de pessic, de caramel a partir del sucre i de mató a partir de la llet són els tres experiments que permeten vehicular l'estructuració del concepte de canvi químic. La preparació d'un pa de pessic és l'experiment paradigmàtic del canvi químic. En ell intervenen diferents canvis en l'estructura del midó de la farina i es produeix un canvi químic amb l'acció del llevat químic, on és molt important la proporció de les substàncies que hi intervenen. Això fa que sigui un experiment central per comprendre el concepte de canvi químic.
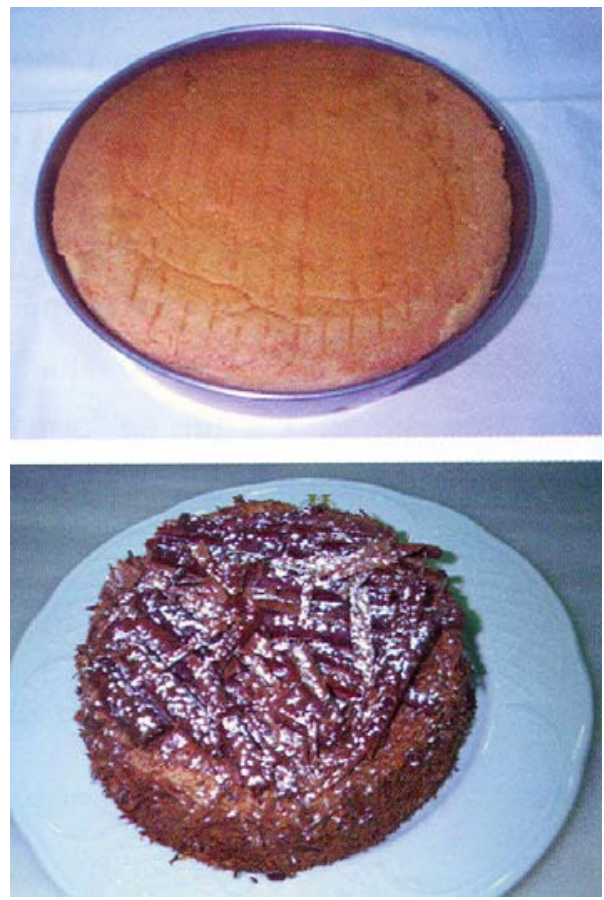

Fig 3. Un parell de pastissos fets a classe

Un cop fet i menjat el pastís, passem a l'explicació química del canvi químic que ha succeït durant el procés, amb les equacions químiques corresponents i les explicacions macroscòpica i microscòpica. Per a això, l'alumnat ha d'elaborar l'informe científic de l'experiment o construir la $V$ heurística, par tal d'elaborar la resposta a la pregunta que la classe proposa contestar.

\section{ALGUNS COMENTARIS FINALS DE VALORACIÓ}

La química de la cuina és rebuda amb entusiasme per l'alumnat: cuinen, aprenen i s'acaben menjant tot allò que preparen, ja siguin mescles i dissolucions per esmorzar o col-loides per berenar. A les noies i als nois els resulta més proper i més significatiu l'estudi de les tècniques de separació de les mescles en el context culinari que no pas el de les tècniques d'un laboratori.

Avui, un element que destaca de manera recurrent en la reflexió didàctica és la necessitat que les noies i els nois s'impliquin en la seva formació. Això és difícil d'aconseguir en el context de laboratori, però en la cuina les emocions i sentiments desenvolupats de manera autònoma per les noies i els nois, que treballen en grup i prenen les seves pròpies decisions sobre les preparacions que cal fer $\mathrm{i}$ com s'organitzen per fer-les, aporta un grau d'entusiasme que reverteix clarament en el nivell d'aprenentatge.

En la meva intervenció docent en l'àmbit de la química de la cuina he pogut observar com les noies $i$ els nois pregunten a les mares i les àvies les receptes o les busquen en llibres de cuina que no havien consultat abans, per fer les seves propostes al grup de treball, S'inventen barreges d'ingredients que siguin bones, es distribueixen la feina i s'organitzen de manera que no falti cap ingredient per preparar el que ha decidit el seu grup de treball, s'entusiasmen amb els resultats que obtenen, procuren que el portaveu del seu grup defensi l'explicació científica d'allò que han preparat i mostren el seu acord o desacord amb les propostes de treball que els faig, com a professora.

Evidentment, acostuma a haver-hi una correlació entre els bons resultats en el procés de modelització del canvi químic d'una noia o un noi i el desenvolupament de les seves destreses en el treball i l'aprenentatge en la cuina-laboratori. Però també hi ha alumnes que no destaquen per la seva excel.lència escolar $i$, no obstant això, troben un bon motiu per treballar en les activitats de la química de la cuina.

La situació actual de l'experiència és plena de futur i perspectives de continuïtat, en la mesura que la introducció de la cuina d'altres cultures pot introduir un element nou de curiositat i servir també d'identificació per a l'alumnat nouvingut a Catalunya. A més, la incorporació de la cuina de mestissatge obre una perspectiva molt interessat per a l'acolliment de l'alumnat estranger. Pot fer una petita contribució a la construcció d'una societat sense fractures socials.

Finalment, mitjançant la reflexió sobre els sabers femenins culinaris, intento presentar a les noies $i$ als nois una sèrie de valors $i$ signes diferents dels que s'han assignat tradicionalment a la 
masculinitat i a la feminitat que avui, malgrat els petits canvis que s'observen encara són majoritaris en la nostra societat. Amb la incorporació de la química de la cuina i la recuperació de l'autoritat científica femenina en les propostes didàctiques, les noies tenen models d'identificació i de referèn- cia que les animen a cursar estudis superiors de ciències.

\section{BIBLIOGRAFIA}

Solsona, Núria (2003). El saber científico de las mujeres. Madrid: Talasa. 